\title{
Certain Profession of Working as Risk Factors for Varicose Veins
}

\author{
${ }^{1}$ Shiksha Sharma, ${ }^{2}$ Minakshi Vashist, ${ }^{3}$ Madan Gopal Vashist, ${ }^{4}$ Kirti Grow, \\ ${ }^{5}$ Ritu Yadav \\ 1,4 Research Scholars, M.D. University, Rohtak, India. \\ ${ }^{2}$ Professor \& Head, Deptt. of Genetics M.D. University, Rohtak, India. \\ ${ }^{3}$ Senior Professor, Deptt. of Surgery, Pt. B.D. Sharma University of Health \\ Sciences, Rohtak, India. \\ ${ }^{5}$ Assistant Professor, Deptt. of Genetics M.D. University, Rohtak, India.
}

\begin{abstract}
Varicose veins are visible surface manifestations of an underlying venous insufficiency syndrome. The present study was designed to investigate the various risks factors behind the occurrence of varicose veins. One hundred fifty five patients of varicose veins were analyzed for various factors. A specialized questionnaire was developed to record detailed information of varicose veins patients. Two way-ANOVA, odds ratio and $\chi^{2}$ test were used to compare the data. Standing occupation was highly significant as compared to sitting (OR= 3.1774; $95 \% C I=i .9528$ to 5.1699). Two way ANOVA revealed statistically significant values for age group $(C I=95 \%, d f=4, p=0.05554)$ whereas sex alone as a factor was found less significant $C I=95 \%,(d f=1$, $p=0.12723)$. Significant association was found between working posture and sex ratio $(p<0.05)$. Working posture and age groups were found to be the most significant risk factors of varicose veins.
\end{abstract}

Key Words: Risk factors, Varicose veins, Occupation and Working posture.

\section{Introduction}

Health is not something that one possesses as a commodity, but connotes rather a way of functioning within one's environment (work, recreation, and living). Though several types of environment exist, it is the physical environment, which plays an important bearing on health. In today's competitive and industrial life man spends most of his time in work place. So, a large extent health is affected by working conditions.

Varicose veins are a typical manifestation of chronic venous insufficiency. It is common vascular abnormality in the world. It occurs, when the one way valves in the vein stop working properly. Veins are blood vessels that returns deoxygenated blood from the outer part of body back to the heart and lungs. When vein becomes abnormal, full of the twists and turns, or enlarged, they are called Varicose Veins. The vein becomes weakened, enlarged and dilated. The veins have permanently lost their ability to carry blood from the legs back up to the heart against the force of gravity. As the blood falls down the legs and pools due to gravity, the veins overfill giving them their typical unsightly bulging appearance.

Varicose veins occur when the vein becomes distended or swollen and the valves which move blood to the heart cannot close properly and start to leak. 20 percent of the population suffers with varicose veins and $2 \%$ have skin changes that may precede venous ulceration [1]. The prevalence of varicose veins increases with age [2-4]. These veins are most commonly found in people who sit or stand in one position for prolonged periods of time, people who habitually sit with their legs crossed, and those who lack proper regular exercise. Female sex, pregnancy, history of varicose vein, Obesity, Standing or sitting for long time and heavy lifting also increase the likelihood of developing varicose veins as they all put increased pressure on the body [5].

In Indian scenario this disease is one of the common surgical problems in low socio-economic class people, which at times compel the patient to change his occupation which is very disturbing [6]. Researcher personally has observed that most of the Indians were unaware of varicose veins, and also their preventive measures. So there is a need to educate the people regarding this condition in order to prevent it. The present study will provide self instructional module regarding prevention of varicose veins in workers.

\section{Methodology}

In the present study, one hundred fifty five patients known to have Varicose Veins disorder were examined from Pt. B. D. Sharma University of Health Sciences, Rohtak, Haryana. The patients selected for this study, were diagnosed with the help of color Doppler examination. Further the patients were followed up and final outcome was evaluated. A thorough history was taken with the help of a special questionnaire which includes occupational conditions, life style and other environmental factors. Ethical clearance was taken from the Institutional Ethical Committee, Rohtak.

The patients were divided into three groups based on the types of work. The group I consisted of office workers or those who do less work or live in same position for long time; the group II consisted of light physical 
laborers mainly including arm and leg movement, no weight lifting and no whole body movements; group III consisted of heavier physical laborers including walking, whole body movement and heavy load handling. The collected data was helpful to find out their role in occurrence of varicose veins. For statistical analysis, Two Way ANOVA was used on the patients of different age groups and gender. The odds ratio was adjusted for sex, working posture, working location and profession. The $\chi^{2}$ test was used to compare the prevalence of varicose veins with other examined characteristics.

\section{Results}

One hundred fifty five patients of varicose veins were studied in the present investigation. Frequency of varicose veins patients was significantly higher in the age group of 21 to 30 years (Fig-1). Two way ANOVA was used on the sample population of varicose veins in different age groups and sex ratio and the interaction of age and sex as a factor was studied. Statistical calculations revealed significant value for age group (CI $=95 \%$, $\mathrm{df}=4, \mathrm{p}=0.05554)$ whereas sex alone as a factor was found less significant $\mathrm{CI}=95 \%,(\mathrm{df}=1, \mathrm{p}=0.12723)$. Prevalence of varicose veins was significantly higher in men in all three professional groups (Fig- 2).

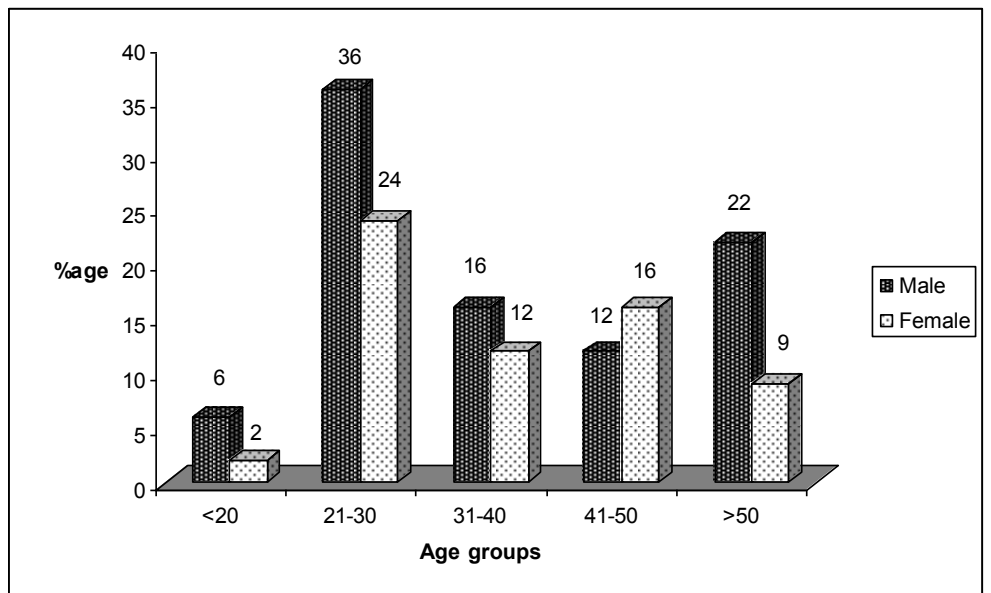

Figure 1: The frequency of varicose veins in comparison to the age groups and sex.

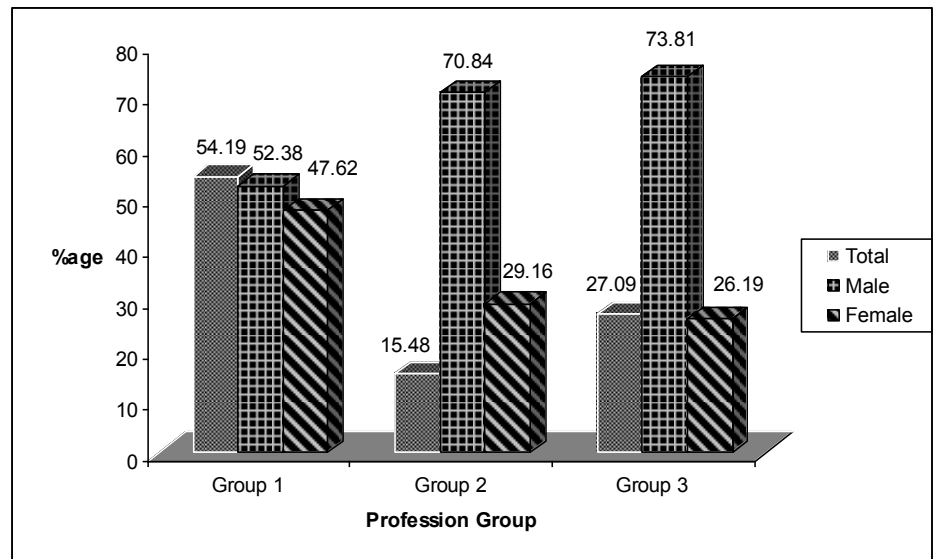

Figure 2: The prevalence of varicose veins in comparison to the profession and sex.

The odds ratio analysis showed that the standing posture at work was highly significant risk factor as compared to those who primarily sit in their workplace $(\mathrm{OR}=3.1774 ; 95 \% \mathrm{CI}=\mathrm{i} .9528$ to 5.1699$)$ and also in those who generally work indoor than outdoor workers $(\mathrm{OR}=0.5499 ; 95 \% \mathrm{CI}=0.3506$ to 0.8627$)$. Frequency of patients who work in low temperature for long time was found high in comparison to those who works in high temperature $(\mathrm{OR}=0.4615 ; 95 \% \mathrm{CI}=0.2930$ to 0.7626$)$. In all three groups of subject, varicose veins was more prevalent in group $1^{\text {st }}$ and group $3 \mathrm{rd}(\mathrm{OR}=6.45$ and 2.374) (Table 1). An odds ratio greater than 1 indicates that the condition or event is more likely to occur in the first group and an odds ratio less than 1 indicates that the condition or event is less likely to occur in the first group. 
Table: 1. Comparison of varicose veins prevalence in relation to the profession, sex, working posture, location and temperature at work place.

\begin{tabular}{|c|c|c|c|c|c|c|}
\hline S.No. & Risk factors & Categories & PRESET & ABSENT & OR & $95 \% \mathrm{CI}$ \\
\hline \multirow[t]{6}{*}{1} & Profession & Group 1 & 84 & 71 & & 3.7715 to \\
\hline & & Group 2 & 24 & 131 & 6.45 & 11.0572 \\
\hline & & Group 1 & 84 & 71 & & 1.7060 to \\
\hline & & Group 3 & 47 & 108 & 2.7186 & 4.3324 \\
\hline & & Group 3 & 47 & 108 & & 1.3653 to \\
\hline & & Group 2 & 24 & 131 & 2.3754 & 4.1328 \\
\hline \multirow[t]{2}{*}{2} & Sex & Male & 92 & 63 & 2.1325 & 1.3553 to \\
\hline & & Female & 63 & 92 & & 3.3555 \\
\hline \multirow[t]{2}{*}{3} & Working Posture & Standing & 78 & 73 & 3.1774 & 1.9528 to \\
\hline & & Sitting & 38 & 113 & & 5.1699 \\
\hline \multirow[t]{2}{*}{4} & Working Location & Outdoor & 66 & 89 & 0.5499 & 0.3506 to \\
\hline & & Indoor & 89 & 66 & & 0.8627 \\
\hline \multirow[t]{2}{*}{5} & Temperature at workplace & High temperature & 63 & 92 & 0.4615 & 0.2930 to \\
\hline & & Low temperature & 92 & 63 & & 0.76269 \\
\hline
\end{tabular}

Group 1- Office workers and those who done less work or living in same position for long time.

Group 2- Light physical labor mainly including arm and leg movement, no weight lifting, and no whole body movement.

Group 3 - Heavier physical labor including walking, whole body movement and heavy load handling.

Chi Square revealed significant values for the association of working posture and sex ratio in varicose veins patients $\left(\chi^{2}=3.977, \mathrm{df}=1, \mathrm{p}\right.$ value $\left.=0.0461\right)(\mathrm{p}<0.05)($ Table 2$)$.

Table 2: Association between sex ratio and working posture of varicose patients.

\begin{tabular}{clll}
$\begin{array}{c}\text { Working } \\
\text { Posture } \\
\text { Sex }\end{array}$ & Standing & Sitting & Total \\
\hline Male & 52 & 18 & 70 \\
Female & 26 & 20 & 46 \\
Total & 78 & 38 & 116
\end{tabular}

*Significant at $\mathrm{p}$ value $<0.05$

\section{Discussion}

In present study we examined the relationship between varicose veins and a comprehensive range of risk factors and their role in occurrence of this disorder.

The major finding from this study was the significantly higher prevalence of varicose veins in men $(\mathrm{OR}=2.1325)$ as compared to women. Higher prevalence of men have been reported in another Indian study [6] and Edinburgh study [7]. In our study, the percentage of women suffering from varicose veins was low i.e $40.65 \%$ as compared to western study done by Kontosic et al; 2000, Baric et al; 1984 and Mimica et al; 1980 [810]. The female patients in this study mainly sought treatment for symptoms and complications rather than for cosmetic reason. The low incidence seen in present study is most probably due to less cosmetic concern in our Indian middle and lower class women. The age distribution showed majority of the patients between the age group 21 to 30 years which was above $45 \%$. These results were found to be almost similar to other studies [6, $11-12]$.

In our study, the frequency of varicose veins was higher $(50.32 \%)(\mathrm{OR}=3.177)$ in person who stands for long time and in only $24.51 \%$ of patients sitting posture was found as a risk factor. Numerous other studies have similarly found that standing for long time is a risk factor for varicose veins [13-18]. The present study revealed that the number of varicose veins patients were higher in those who generally work indoors $(\mathrm{OR}=$ 0.5499 ) and also indicated that low temperature at workplace may be a risk factor for varicose veins. But in population based study of Rijeka, the high temperature at workplace was the risk factor for varicose veins and revealed the similar results regarding high frequency in indoor workers [8].

Varicose veins is a common condition in the young and middle aged peoples. This study suggests higher frequency of male patients which due to their lifestyle. It is concluded that standing or remaining in same posture for long time are the causing factors for varicose veins. So, the present study would help in the early detection of associated risk factors of varicose veins which would be quite helpful to reduce the risk of the disease. 


\section{Acknowledgment}

The authors are grateful to Deptt. of Surgery, Pt. B.D. Sharma University of Health Sciences, Rohtak for studying varicose veins patients. CSIR (09/382(0128)/2008-EMR-1), New Delhi is gratefully acknowledged for giving fellowships to research scholar and providing funds for carrying out the research work.

\section{Reference}

[1] Johnson G. The management of venous disorders in Rutherford RB. Vasc surg. 1994; 4(2), 1671-882.

[2] Cesarone MR, Belcaro G, Nicolaides AN, Geroulakos G, Griffin M, Incandela L, De Sanctis MT, Sabetai M, Geroulakos G, Agus G, Bavera P, Ippolito E, Leng G, Di Renzo A, Cazaubon M, Vasdekis S, Christopoulos D and Veller M. 'Real' epidemiology of varicose veins andchronic venous diseases: the San Valentino vascular screening project. Angiol. 2002; 53:119-130.

[3] Criqui MH, Jamosmos M, Fronek A, Denenberg JO, Langer RD, Bergan J and Golomb BA. Chronic venous disease in an ethnically diverse population: the San Diego Population Study. Am J Epidemiol. 2003; 158:448-456.

[4] Kroeger K, Ose C, Rudofsky G, Roesener J, Hirche H. Risk factors for varicose veins. Int Angiol. 2004; $23: 29$ e34.

[5] Black J and Jacobes. Luckman and Sorensons medical surgical nursing $4^{\text {th }}$ edition. Philadelphia: W.B. Suanders company. 2000; (4).

[6] Pramod M, Shalish E and Chhaya J. Study of Clinical Features and Management of Varicose Veins of Lower Limb. J Clinic Diagno Research. 2011; 5(7):1416-1420.

[7] Evans CJ, Fowker FG, Ruckley CV and Lee AJ. Prevalence of varicose veins and chronic venous insufficiency in men and women of general population on: Edinburgh Vein Study. J Epidimiol Comm Health. 1999; 53:149-153.

[8] Konto ŝî́ I, Vukeli M, Dreŝcik I, et al. Work conditions as risk factors for varicose veins of the lower extremities in certain professions of the working population of Rijeka. Acta Med Okayama. 2000; 54:33-8.

[9] Barić LJ. The disease of aorta, arteries and veins; in internal medicine in practice. 1984; 683-699.

[10] Mimica M, Pavlinović Ž and Malinar M. Varicose veins in legs in working population. Arh Hig Rada Toksiko. 1977; 28:145-155.

[11] Khan B, Khan, Greaney G, Blairs D. Prospective randomized trial comparing sequential avulsion with stripping of the long sapherrous vein. Br J Surg. 1996; 83: 1559-62.

[12] Singh S, Lees TA, Donlon M, Harris N, Beard JD. Improving the preoperative assessment of varicose. Br J Surg. 1997; 84: 801-02

[13] Arandelovic P, Zivadinovic N and Jovanovic Z. Occurrence of varicosities on lower extremities in three groups of workers and some aspects of work capacity evaluation; in phlebology, symposium on pathological conditions of venous circulation. Ljublijana. 1976; $755-761$.

[14] Carpentier PH, Maricq HR, Biro C, Poncot-Makinen CO and Franco A. Prevalence, risk factors, and clinical patterns of chronic venous disorders of lower limbs: A population-based study in France. J Vasc Surg. 2004; 40:650-659.

[15] Sisto T, Reunanen A, Laurikka J, Impivaara O, Heliovara M, Knekt P, and Aromaa A. Prevalence and risk factors of varicose veins in lower extremites: Mini- finland health survey. Eur J Surg. 1995; 161:405-414.

[16] Komsuoglu B, Goldeli O, Kulan K Cetinarslan B and Komsuoglu SS. Prevalence and risk factors of varicose veins in elderly population. Gerobntol. 1994;40: 25-31.

[17] Krijnen RMA, de Boer EM, Bruynzeel DP. Epidemiology of venous disorders in the general and occupational populations. Epidemiol Rev. 1997; 19:294-309.

[18] Radak Đ, Đukic V, Maksimović Ž, Kaleziĉ V, Sindelić R, Đukanović B, Ĉinara I, Lukić J, Pelivan N and Rosato E, 1989. 